4 Smith, I, Lobascher, M, and Wolff, O H, in Proceedings of the 10th Symposium of the Society for the Study of Inborn Errors of Metabolism, ed J W T Seakins, R A Saunders, and C Toothill, p 41. Edinburgh, Churchill Livingstone, 1973.

5 Smith, I, et al, Annals of Clinical Biochemistry, 1977, 14, 134.

${ }^{6}$ Bickel, H, and Grubel-Kaiser, S, Deutsche medizinische Wochenschrift, $1971,96,1420$.

7 Smith, I, and Francis, D E M, in Textbook of Paediatric Nutrition, ed D S McLaren and D Burman, p 263. Edinburgh, Churchill Livingstone, 1976.

${ }^{8}$ Bickel, H, et al, in Phenylketonuria and some other Inborn Errors of AminoAcid Metabolism, ed H Bickel, F P Hudson, and L I Woolf, p 241. Stuttgart, Georg Thieme, 1971.

- Bentovim, A, Archives of Disease in Childhood, 1968, 43, 745.

10 Smith, I, and Wolff, O H, Lancet, 1974, 1, 1229.

11 Bickel, H, Monatsschrift fürKinderheilkunde, 1966, 114, 23.

12 Lutz, P, in Phenylketonuria and some other Inborn Errors of Amino-Acid Metabolism, ed H Bickel, F P Hudson, and L I Woolf, p 258. Stuttgart, Georg Thieme, 1971.

13 Lemag Working Party, fournal of Clinical Pathology, 1971, 24, 576.

14 McCaman, M W, and Robins, E, fournal of Laboratory and Clinical Medicine, 1962, 59, 885.

15 Hudson, F P, and Hawcroft, J, in Proceedings of the 10th Annual Symposium of the Society for the Study of Inborn Errors of Metabolism, ed I W T Seakins, R A Saunders, and C Toothill, p 51. Edinburgh, Churchill Livingstone, 1973.
${ }^{16}$ Cabalska, B, et al, in Proceedings of the Third Congress of the International Association for the Scientific Study of Mental Deficiency, ed D A A Primrose, p 548. Warsaw, Polish Medical Publishers, 1973.

17 Cabalska, B, et al, European fournal of Pediatrics, 1977, 126, No 4, 253.

18 Brown, E S, and Warner, R, Psychological Medicine, 1976, 6, 287.

10 Van Leeuwen, W S Donker, D N J, and Van Sprang, F J, in Growth and Development of the Brain, ed M A B Brazier, p 275. New York, Raven Press, 1975.

${ }^{20}$ Frankenberg, W K, Goldstein, A D, and Olson, C O, American fournal of Mental Deficiency, 1973, 77, 524.

${ }^{21}$ Anderson, V E, Segal, F S, and Brecht, H H, Pediatric Research, 1976, 10, 10.

${ }^{22}$ Wood, B, Developmental Medicine and Child Neurology, 1976, 18, 657.

${ }^{23}$ Bickel, H, Gerrard, J, and Hickmans, E M, Lancet, 1953, 2, 812.

24 Silverman, $M$, and Guthrie, $R$, personal communication, 1977.

${ }^{25}$ Horner, F A, et al, New England fournal of Medicine, 1962, 266, 79.

26 Johnson, F, Clinical Pediatrics, 1972, 11, 148.

27 Kang, E S, Sollee, N D, and Park, S G, Pediatrics, 1970, 46, 881.

${ }^{28}$ Holtzman, N A, Welcher, D W, and Mellits, E D, New England fournal of Medicine, 1975, 293, 1121.

${ }^{29}$ Berman, J L, and Ford, R, fournal of Pediatrics, 1970, 77, 764.

30 Dobson, J C, et al, Pediatrics, 1976, 58, 53.

31 Sutherland, I, Hudson, F P, and Hawcroft, J, MRC/DHSS Phenylketonuria Register Newsletter No 5. London, MRC/DHSS, 1978.

(Accepted 18 fuly 1978)

\title{
Two types of febrile seizure: anoxic (syncopal) and epileptic mechanisms differentiated by oculocardiac reflex
}

\author{
J B P STEPHENSON
}

British Medical fournal, 1978, 2, 726-728

\section{Summary and conclusions}

The duration of cardiac asystole induced by ocular compression was measured in 100 consecutive children referred for electroencephalographic examination after one or more febrile convulsions (FC). The children were classified into three groups-namely, those with anoxic FCs, those with epileptic FCs, and "others"-according to the appearances of the FC and the electroencephalogram (EEG). In 14 children the description of the FC suggested non-epileptic anoxic cerebral seizures such as are seen after prolonged syncope or breath-holding. In 35 children the FCs were assumed to be epileptic in mechanism on the basis of unilateral (hemiclonic) twitching, known cerebral disease, a family history of epilepsy, or spikes on the EEG. In the 51 "others" the FCs could not be classified. Definitely abnormal asystole (four seconds or over) was induced by ocular compression in half the anoxic group, in $16 \%$ of the "others," but in none of the epileptic group. The differences between the degree of asystole induced in each of the three groups was highly significant $(P=0.005)$.

These results support the hypothesis that vagalmediated cerebral ischaemic anoxia is implicated in the genesis of FCs that resemble anoxic seizures and in a substantial number of those without an obvious epileptic mechanism. The significance, genetics, management, and prognosis of FCs must now be re-examined in this light.

Fraser of Allander Unit and Electroencephalography Department, Royal Hospital for Sick Children, Glasgow G3 8SJ

J B P STEPHENSON, MRCP, consultant in paediatric neurology

\section{Introduction}

Febrile convulsion (FC) is the most common neurological disorder of childhood. ${ }^{1}$ It is frightening to witness, and may sometimes lead to lasting brain damage, ${ }^{23}$ but exactly what it is and why it affects only certain children are ill understood. It is usually assumed ${ }^{145}$ that FCs are epileptic in mechanism-that is, that they result from excessive hypersynchronous cerebral neuronal discharges ${ }^{6}$-even though epilepsy rarely follows in later life. $^{7}$ An alternative suggestion ${ }^{8}{ }^{8}$ that the convulsions are primarily anoxic or syncopal-that is, that they are associated with reduced cerebral blood flow and reduced cerebral cortical neuronal activity ${ }^{6}$-has been almost totally ignored. ${ }^{10}$ In a recent study ${ }^{11}$ of reflex anoxic seizures presumed to result from vagal-mediated cardiac arrest after unpleasant stimuli ${ }^{12}$ the retrospective incidence of FCs was $14 \%$, four times the expected incidence of $3.4 \% \%^{7}(\mathrm{P}<0.002)$. Furthermore, the FCs in that study did not appear from the history to differ in character from afebrile reflex anoxic seizures suffered by the same children. I have therefore carried out a study to investigate prospectively a series of children with a history of FCs, first making a clinical judgment on the type of FC-whether anoxic, epileptic, or uncertain-and then using a physiological technique 11 that elicits the oculovagal or oculocardiac reflex, which is hypersensitive in syncope, ${ }^{13}$ to differentiate between reflex anoxic and epileptic seizures.

\section{Patients and methods}

I studied 100 consecutive children aged under 8 years referred to the electroencephalography department with a history of FCs (defined as any seizure with fever of $38^{\circ} \mathrm{C}$ or over). There were no exceptions, as those who also had, for example, afebrile seizures or cerebral disease were included. Before the study, in accordance with hospital policy, children who had had FCs and were referred for electroencephalographic examination were mostly atypical or had had recurrences. During the study there was an increased referral 
after a single "simple" FC, but atypical and multiple FCs continued to be overrepresented. Of the 100 children studied, 45 had had a single $\mathrm{FC}$; in the remaining 55 there had been one or more recurrences. In each case the history was reviewed or retaken, the EEG examined, and an immediate classification made into one of the following three groups:

Anoxic-Children were placed in this group when the description of the FC suggested an anoxic cerebral seizure ${ }^{614}$ with tonic extension and no more than minor jerking or when it resembled other typical anoxic seizures due to pain, etc, ${ }^{11}$ that had occurred in the same child. In 11 children the FCs were tonic and not clonic; in two of them the tonic FC resembled reflex anoxic seizures that had occurred in the same children. In one child the tonic FC was accompanied by a few jerks of the legs but the description was typical of an anoxic seizure. FCs in two other children resembled their limp atonic reflex anoxic seizures. Three children with tonic seizures were excluded from this group and the FCs classified as epileptic, one because of a history of afebrile hemiclonic seizures and two because of spikes on the EEG. The remaining 14 children constituted the group with anoxic FCs.

Epileptic ${ }^{6}$-Children were placed in this group when the FC consisted of unilateral (hemiclonic) or predominantly lateralised twitching ( 16 children); when eye flickering or blinking was described (three); when there was known or suspected cerebral disease (five; two with mental handicap, one with congenital right hemiplegia, one with previous meningitis and seizure, and one with an additional history of an afebrile hemiclonic seizure); when there was a family history of epilepsy as distinct from FCs (three); and when the EEG contained spikes (eight). Thus this group comprised 35 children.

Others-This group comprised the remaining 51 children whose convulsions could not be classified as either anoxic or epileptic. Most of the FCs in these children were described as generalised symmetrical twitching, commonly with upward ocular deviation and tonic extension at the onset.

After the procedure had been explained to the mother or attendant ocular compression was carried out for 10 seconds with the child supine and the EEG and electrocardiogram running, as previously described. 11 The maximum interval between ORS complexes after the onset of ocular compression was measured to within 0.1 second and recorded as the duration of asystole. The durations of asystole in the children in each of the three groups were compared, and an exact probability was derived using the generalised likelihood ratio test. ${ }^{15}$

A further 93 children with adequate histories and miscellaneous disorders including epilepsy but excluding reflex anoxic seizures, ${ }^{11}$ syncope, ${ }^{13}$ and FC were similarly studied as a control group.

\section{Results}

The distribution of age at ocular compression was similar in the three groups both for children who had had only one FC and for those who had had recurrences (table). There were more boys in the anoxic group (male to female ratio $1.8: 1$ ) and the "others" $(1.55: 1)$ but more girls in the epileptic group $(0.94: 1)$. The duration of asystole on ocular compression was longer in the anoxic group, half of the children having cardiac arrest of four seconds or more (see fig) Ocular compression had little effect in the epileptic group, and asystole did not reach four seconds in any of these children. The results in the others-children with unclassified FCs-were intermediate between those in the anoxic and epileptic groups, and in eight $(16 \%)$ of these children asystole lasted four or more seconds, an abnormal response. ${ }^{112} \mathrm{By}$ taking the individual asystole values and comparing

Number of children in each age group according to type of febrile convulsion (FC). Groups were divided into children tested after one FC and those who had had two or more

\begin{tabular}{|c|c|c|c|c|c|c|c|c|c|c|c|}
\hline \multicolumn{3}{|c|}{ Age at ocular compression } & . & $-\frac{1}{2}$ & -1 & $-1 \frac{1}{2}$ & -2 & -3 & -4 & -5 & -8 \\
\hline \multicolumn{12}{|c|}{ One febrile convulsion only } \\
\hline $\begin{array}{l}\text { Anoxic ... } \\
\text { Epileptic.. } \\
\text { Other ... }\end{array}$ & $\begin{array}{l}\cdots \\
\cdots\end{array}$ & $\begin{array}{l}. \\
\because\end{array}$ & $\begin{array}{l}\cdots \\
\cdots\end{array}$ & 1 & $\begin{array}{l}1 \\
5\end{array}$ & $\begin{array}{l}2 \\
2 \\
7\end{array}$ & $\begin{array}{l}4 \\
3\end{array}$ & $\begin{array}{l}2 \\
3 \\
2\end{array}$ & $\begin{array}{l}1 \\
3 \\
3\end{array}$ & $\begin{array}{l}1 \\
1 \\
1\end{array}$ & 3 \\
\hline \multicolumn{12}{|c|}{ Recurrent febrile convulsions } \\
\hline $\begin{array}{l}\text { Anoxic ... } \\
\text { Epileptic.. } \\
\text { Other ... }\end{array}$ & 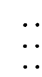 & 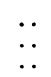 & $\begin{array}{l}\cdots \\
\cdots\end{array}$ & & 1 & $\begin{array}{l}1 \\
2 \\
1\end{array}$ & $\begin{array}{l}1 \\
4 \\
5\end{array}$ & $\begin{array}{l}1 \\
6 \\
7\end{array}$ & $\begin{array}{l}1 \\
1 \\
6\end{array}$ & $\begin{array}{l}2 \\
2 \\
3\end{array}$ & $\begin{array}{l}1 \\
6 \\
4\end{array}$ \\
\hline
\end{tabular}

each group with the other two the differences between the groups were shown to be highly significant $(P=0.005)$.

Of the 93 control children, $69(74 \%)$ had asystole of less than two seconds on ocular compression and $23(25 \%)$ asystole of more than two seconds but less than four; only one child (1\%) had an asystole of more than four seconds.

\section{Discussion}

This is the first report of a continuing study of the oculocardiac reflex in FCs. Children with FCs that from the history are judged to be anoxic have an excessive response to ocular compression. The degree of asystole induced in these children did not differ from that found ${ }^{11}$ in eight out of 58 children primarily assessed because of reflex anoxic seizures (see figure) but in whom some of the seizures were induced by fever and so by definition were FCs.

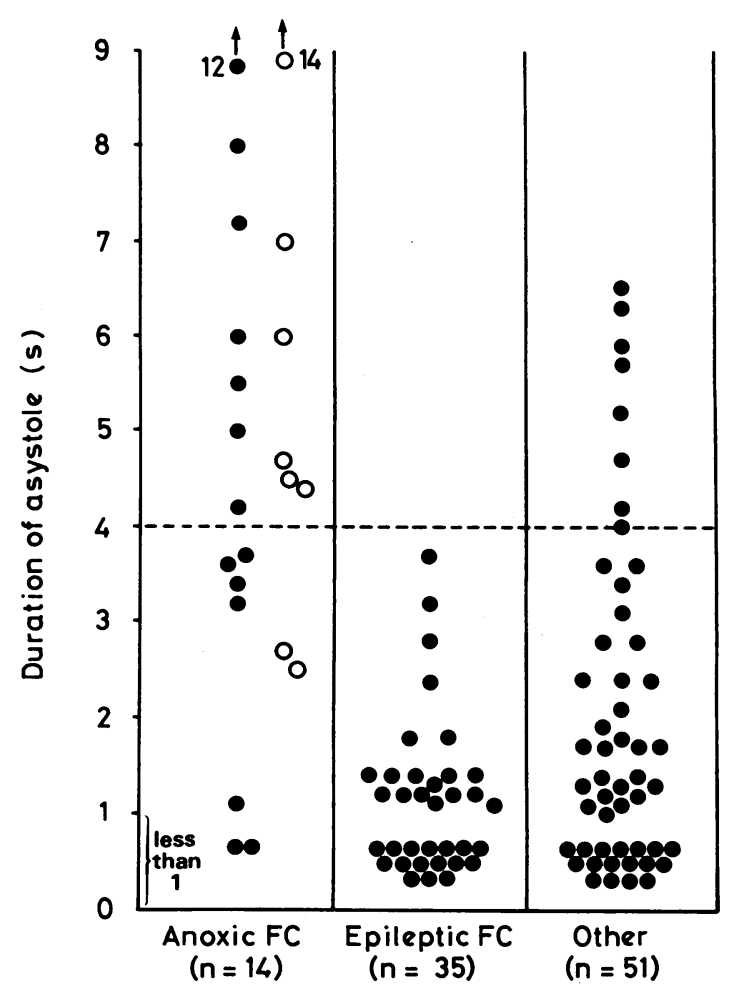

Duration of cardiac asystole induced by ocular compression in 100 consecutive children with FC. $=$ Children in present series. $O=$ Eight additional children studied previously. ${ }^{11}$ Asystole of four or more seconds is abnormal.

Children with FCs that on clinical grounds or from the EEG were strongly suspected to be epileptic in mechanism, did not show hyperactive oculocardiac responses. They did not differ from the control group or from children previously studied. ${ }^{12}$

Perhaps the most important observation is that the largest group, of children with unclassified or indeterminate FCs ("others"), contained an appreciable proportion of children with abnormally prolonged asystole on ocular compression, the asystole equalling or exceeding four seconds in $16 \%$ of cases. This suggests that vagal-mediated cardioinhibition (ischaemic anoxia) accounts for a substantial proportion of FCs that do not have an obvious epileptic mechanism, even though the form of the FC appears more complex-for example, clonic-than in afebrile reflex anoxic seizures. ${ }^{11}$

Although an epileptic mechanism for FCs has been implicitly assumed recently, ${ }^{14516}$ this was not always so. McGreal, ${ }^{8}$ whose findings have been published only in abstract, ${ }^{17}$ concluded that most FCs (described in detail ${ }^{8}$ ) were "fundamentally 
anoxic, not epileptic." Gastaut and Gastaut ${ }^{9}$ induced 10 frank anoxic seizures ${ }^{18}$ by ocular compression in 44 children with FCs but were unable to induce anoxic seizures in 66 children with symptoms of a cerebral lesion. Gastaut et al, ${ }^{19}$ summarising the discussion and conclusions of the 1959 International Colloquium on Cerebral Anoxia and the EEG, said "two-thirds of attacks of unconsciousness in infancy (which are called "convulsions') are in reality syncope due to cerebral ischaemia brought about by cardio-inhibitory reflexes." More recently, however, Gastaut ${ }^{6}$ proposed that most FCs were epileptic, ${ }^{20}$ with a familial predisposition. Evidence from the present study suggests that the anoxic mechanism is at least as important as an epileptic one in FCs, particularly since, because of hospital referral policy, epileptic FCs were overrepresented in this study.

Numerous trials of antiepileptic drugs are now being carried out throughout the world on children with FCs. It is difficult to see how useful conclusions can be reached unless the investigators attempt to differentiate between anoxic and epileptic FCs and consider the interactions between each of these mechanisms and any preceding neurological abnormality in the child. ${ }^{7}$

I thank Miss G M Block and the staff of the electroencephalography department for tireless co-operation; the department of medical illustration, Royal Hospital for Sick Children; and Dr K R Clarke, department of statistics, University of Glasgow, for the exact possibility analyses. The study would have been impossible without the sustained help of many paediatricians who referred the children, and the tolerance of the children and their parents.

\section{References}

${ }^{1}$ Millichap, J G, Febrile Convulsions. London, Collier-MacMillan, 1968. 2 Ounsted, C, Lindsay, J, and Norman, R, Biological Factors in Temporal Lobe Epilepsy. London, Heinemann, 1966.

${ }^{3}$ Aicardi, J, and Chevrie, J-J, in Brain Dysfunction in Infantile Febrile Convulsions, ed M A B Brazier and F Coceani, p 247. New York, Raven Press, 1976.

${ }^{4}$ Lennox-Buchthal, M, Febrile Convulsions: a Reappraisal. Amsterdam, Elsevier, 1973.

${ }^{5}$ Brazier, M A B, and Coceani, F, eds, Brain dysfunction in Infantile Febrile Convulsions. New York, Raven Press, 1976.

${ }^{6}$ Gastaut, H, Dictionary of Epilepsy, part 1, definitions. Geneva, WHO, 1973.

7 Nelson, K B, and Ellenberg, J H, New England Fournal of Medicine, 1976, 295, 1029.

${ }^{8}$ McGreal, D A, Convulsions in Childhood. MD thesis, University of St Andrews, 1957.

${ }^{9}$ Gastaut, H, and Gastaut, Y, Electroencephalography and Clinical Neurophysiology, 1958, 10, 607 .

10 Stephenson, J B P, British Medical fournal, 1977, 2, 45.

11 Stephenson, J B P, Archives of Disease in Childhood, 1978, 53, 193.

12 Lombroso, C T, and Lerman, P, Pediatrics, 1967, 39, 563.

13 Gastaut, H, and Fischer-Williams, M, Lancet, 1957, 2, 1018.

14 Gastaut, H, in Handbook of Clinical Neurology, ed P J Vinken and G W Bruyn, vol 15, p 815. Amsterdam, North-Holland, 1974.

16 Kendall, M G, and Stuart, A, The Advanced Theory of Statistics, vol 2. London, Griffin, 1961.

${ }^{16}$ Lennox-Buchthal, M A, in Brain Dysfunction in Infantile Febrile Convulsions, ed M A B Brazier and G Coceani, p 327. New York, Raven Press, 1976.

17 McGreal, D A, American fournal of Diseases of Children, 1956, 92, 504.

18 Gastaut, H, and Gastaut, Y, Revue Neurologique, 1957, 96, 161.

19 Gastaut, H, Fischgold, H, and Meyer, J S, in Cerebral Anoxia and the Electroencephalogram, ed H Gastaut and J S Meyer, p 599. Springfield, Illinois, Thomas, 1961.

20 Gastaut, H, and Tassinari, C A, Epilepsia (Amsterdam), 1966, 7, 92.

(Accepted 18 fuly 1978)

\title{
Sampling pure fetal blood by fetoscopy in second trimester of pregnancy
}

\author{
C H RODECK, S CAMPBELL
}

British Medical fournal, 1978, 2, 728-730

\section{Summary and conclusions}

A technique for fetal blood-sampling in the second trimester of pregnancy (between 16 and 22 weeks' gestation) combining fetoscopy with real-time ultrasound was used in 48 attempts at fetal blood-sampling. Specimens containing fetal red cells with or without amniotic fluid or maternal blood, and adequate for diagnosing haemoglobinopathies, were obtained in 45 of the $\mathbf{4 8}$ fetoscopies. Sampling was successful in all 18 patients with a posterior placenta, and in 27 of the 30 with an anterior placenta. In 22 of the last 27 consecutive fetoscopies pure fetal blood was taken; the placenta was anterior in 16 and posterior in six. Out of 17 cases sampled between 18 and 22 weeks' gestation pure fetal blood was obtained in 16 . The volume of the samples varied from 50 to $500 \mu 1$.

The ability to obtain pure fetal blood consistently even when the placenta is anterior will increase knowledge of fetal physiology and the scope of prenatal diagnosis.

\footnotetext{
Department of Obstetrics and Gynaecology, King's College Hospital, London SE5 8RX

C H RODECK, MB, MRCOG, lecturer

S CAMPBE LL, FRCOG, professor
}

\section{Introduction}

Fetal red cells have been obtained in the second trimester by placentocentesis ${ }^{1}$ and by fetoscopy. ${ }^{2}$ The first technique can be used whatever the placental site, but the anterior placenta has hitherto been regarded as a contraindication to fetoscopy. The specimens obtained by either technique have usually consisted of a mixture of fetal and maternal blood or amniotic fluid, or of all three, with fetoscopy yielding a higher proportion of fetal red cells. Such specimens are adequate for prenatal diagnosis of haemoglobinopathies, but greater reliability in obtaining whole fetal blood, and thus pure fetal serum, would widen the scope of fetal investigation to include biochemical abnormalities that cannot be diagnosed from an analysis of amniotic fluid or fetal red cells.

We found that fetal blood sampling by fetoscopy may be performed when the placenta is anterior, and that samples of pure fetal blood, uncontaminated by maternal blood or amniotic fluid, can be reliably obtained.

\section{Patients and methods}

Gestational age is checked by an ultrasound scan and the timing of the fetoscopy planned; for diagnosing a haemoglobinopathy, fetoscopies may be done after 16 weeks' gestation, but better fetal blood ? samples are obtained after 18 weeks. When it is important to obtain pure fetal blood-for example, in carriers of Duchenne's muscular dystrophy - the procedure should take place at 18-20 weeks. A 